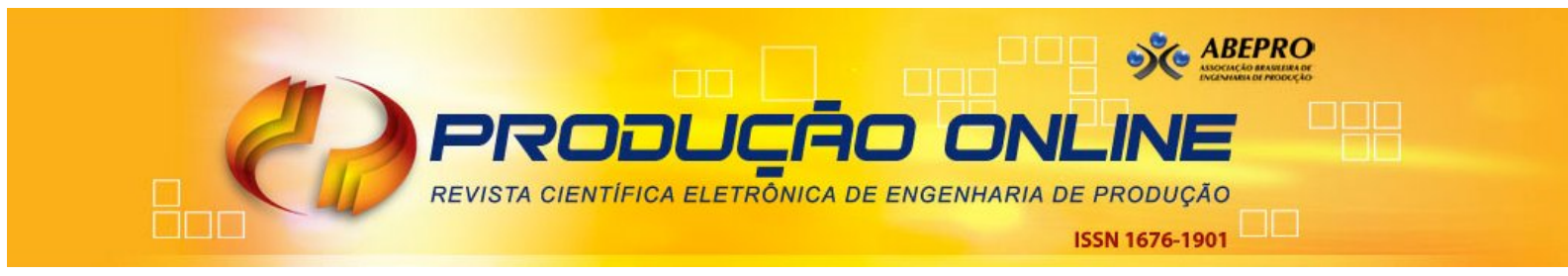

\title{
GESTÃO AMBIENTAL EM EMPRESAS NASCIDAS NO RIO GRANDE DO SUL - UM ESTUDO COMPARATIVO COM OUTRAS EMPRESAS BRASILEIRAS
}

\section{ENVIRONMENTAL MANAGEMENT IN COMPANIES FROM RIO GRANDE DO SUL - A COMPARATIVE STUDY WITH OTHER BRAZILIAN COMPANIES}

\author{
Carlos Candido da Silva Cyrne* E-mail: cyrne@univates.br \\ Claus Haetinger* E-mail: chaet@univates.br \\ Claudete Rempel* E-mail: crempel@univates.br \\ *Centro Universitário Univates, Lajeado, RS
}

Resumo: Este artigo objetiva descrever como as empresas têm gerido as questões ambientais e realizar uma comparação entre as empresas nascidas no Rio Grande do Sul - RS e as demais empresas brasileiras. Este trabalho foi desenvolvido a partir de dados publicados pela Empresa Jornalística Análise Editorial, sobre as práticas de gestão ambiental utilizadas pelas empresas brasileiras. Tomou-se por base a sétima edição do anuário Análise Gestão Ambiental que contemplou 853 empresas, 25 bancos e 237 Organizações não Governamentais - ONGs, sendo avaliados 28 diferentes ramos da economia. A pesquisa está classificada como aplicada; o método de abordagem do problema é quantitativo; em relação aos fins é descritivo; quanto aos meios, o estudo valeu-se de pesquisa bibliográfica e de dados secundários. Os resultados encontrados apontam para o uso da ISO 14001, como principal ferramenta de gestão ambiental e uma defasagem das empresas nascidas no Rio Grande do Sul - RS, sendo possível afirmar que as demais empresas brasileiras se encontram em um estágio mais avançado em relação às práticas de gestão ambiental.

Palavras-Chave: Gestão Ambiental. Ciências Ambientais. Empresas Gaúchas. Empresas Brasileiras.

Abstract: This paper aims to describe how companies have managed the environmental issues, which kind of instruments are used for this purpose, comparing companies from the state of Rio Grande do Sul and the rest of Brazil. This work was developed using data published by Análise Editorial magazine about the environmental management practices that have been used by Brazilian companies. Data was obtained from the seventh edition of the yearbook Análise da Gestão Ambiental, which includes 853 companies, 25 banks and 237 non-governmental organizations (NGOs) and 28 different economy branches. The research nature is classified as applied or technological; the approach method is quantitative; and, the study has a descriptive porpouse, since it exposes the characteristics of different companies; using literature and secondary data. The results point to the use of ISO 14001 as the main tool for environmental management and a lag of local companies. It may be asserted that other Brazilian companies are in an advanced stage regarding the environmental management practices compared to companies from Rio Grande do Sul.

Keywords: Environmental Management. Environmental Sciences. Gaúchas Companies. Brazilian Companies.

\section{INTRODUÇÃo}

Para que se possa tratar a questão ambiental de forma adequada, muito ainda necessita se feito, pois evidências sobre os impactos ecológicos das ações 
humanas colocam em avaliação as usuais formas de gestão das relações homemsociedade-natureza. As consequências do antropocentrismo têm sido grandes, afetando as condições de vida das pessoas e permitindo que se questionem os modelos de desenvolvimento social e econômico adotados pela sociedade.

Segundo Gallardo-Vázquez, Sanchez-Hernandéz e Martínez-Azúa (2013) é preciso realizar um diálogo entre os representantes dos diferentes grupos de interesses, considerando a comunicação como elemento chave para fazer com que a temática ambiental tenha como foco a interdisciplinaridade. É importante perceber que o avanço econômico, social e a preservação ambiental devem ser perseguidos concomitantemente (variáveis que eram tratadas separadamente).

O conceito de desenvolvimento sustentável da Comissão Mundial sobre Meio Ambiente e Desenvolvimento da Organização das Nações Unidas (Comissão Brundtland) é aquele que contempla a preservação dos recursos naturais na perspectiva de garantir a sua disponibilidade para gerações futuras. De acordo com Irimie, Gal e Dumitrescu (2014), Kusakabe (2013), Karagülle (2012), o desenvolvimento sustentável foi definido como aquele que permite satisfazer as necessidades do presente, sem comprometer as necessidades das gerações futuras.

Avanços têm ocorrido no uso de instrumentos técnicos, políticos e legais para a construção de uma política de meio ambiente, o que se torna indispensável no processo de gestão das empresas. Considerando os últimos anos, saltos quantitativos foram dados, em especial no que se refere à consolidação de práticas e formulação de diretrizes que tratam a questão ambiental de forma sistêmica e integrada.

Em função dos avanços da tecnologia e dos meios de comunicação, muitos dos problemas ambientais ainda estão sendo descobertos. Estes avanços trouxeram à tona que as empresas são uma das responsáveis, ao lado dos poderes públicos, e dos próprios consumidores, como afirmam Ocampo, Perdomo-Ortiz e Castaño (2014), de apresentarem e desejarem produtos que tenham procedência em processos sustentáveis, bem como se não há uso de mão-obra escrava, exploração do trabalho infantil, enfim, a responsabilidade é da sociedade.

A preocupação com a gestão ambiental não é recente e cresce de importância continuamente, à medida que os recursos naturais se tornam cada vez mais escassos e, consequentemente, com um custo de aquisição maior. Isto faz com que 
as empresas precisem buscar alternativas para manterem-se competitivas, atentando para a variável ambiental como uma ferramenta gerencial, que pode sustentar a busca pela competitividade, a partir do momento que contribui para a melhoria das condições de vida da sociedade. Uma nova visão a respeito das questões ambientais pelo setor empresarial conduz a ver o meio ambiente como oportunidade e não como um problema.

Alperstedt, Quintella e Souza (2010) afirmam que desde a década de 60 há preocupação com a questão ambiental, com um crescente interesse popular e gerencial sobre o tema, paralelamente ao surgimento de legislações ambientais em todo o mundo, mas é possível voltar ainda mais no tempo e dizer que desde a Revolução Industrial tornou-se necessário atentar para o possível esgotamento dos recursos naturais, pois a capacidade do homem de transformar o meio natural aumentou significativamente trazendo consequências positivas e negativas. De acordo com Ramalho e Sellitto (2013), primeiramente a capacidade de modificar o ambiente foi saudada como algo positivo, pois trouxe expressivo avanço econômico. Porém, a partir da década de 60 surgiu uma visão mais pessimista em relação à exploração da natureza com fins econômicos.

Gerir os empreendimentos, de forma a diferenciar os que demonstram atenção com as questões ambientais dos que não o fazem passou a ser parte da preocupação dos empresários.

As empresas tomando consciência desta nova situação estão se movimentando para atender: a) às exigências legais; b) à fiscalização; c) aos custos; d) à tecnologia requerida; e) as informações, respondendo a pressão (interna e externa) sobre a imagem da empresa; f) aos requisitos apresentados pelo mercado consumidor que passou a exigir produtos "ambientalmente corretos".

Surgem estratégias verdes e produtos verdes, a chamada consciência verde. É preciso encontrar uma nova forma de produzir e consumir, pois só assim poder-seá mitigar os efeitos nocivos sobre o meio ambiente. Para tanto, é fundamental o engajamento das empresas na busca de uma gestão ambiental eficaz. É preciso passar a produzir de uma maneira dita sustentável, evitando assim, o comprometimento das gerações futuras. Como afirma Donaire (1994), a proteção ao meio ambiente deixa de ser uma exigência passível de punição ou de multas para inserir-se no rol das oportunidades e ameaças advindas do ambiente concorrencial. 
A relação entre as empresas e o meio ambiente tem de ser entendida tomando por base os conceitos apresentados pela teoria de sistemas, que afirma que as empresas são um sistema aberto, formada por partes, que interligadas, formam um todo, que influenciam e são influenciadas por variáveis controláveis e incontroláveis.

A dimensão territorial do Brasil contempla a existência de diferentes culturas, o que permite afirmar que a forma de gerir é distinta nas diferentes regiões e nos diferentes estados do país. Sem a intenção de sugerir que há uma melhor ou pior forma de gerir e que existem diferentes países no Brasil, este texto procura estabelecer um comparativo das práticas de gestão ambiental das empresas nascidas no Rio Grande do Sul em relação às empresas do restante do Brasil, a partir dos dados apresentados na Revista Análise - Gestão Ambiental 2013-2014. A Editora Análise que vem publicando periodicamente os resultados levantados junto às empresas brasileiras viabiliza esta comparação.

\section{GESTÃO AMBIENTAL - UMA BREVE REVISÃO}

A modernidade trouxe a internacionalização, o consumismo e a dita globalização, com a consequente inter-relação entre as nações e neste contexto as questões ambientais realçam uma interdependência, pois desconhecem fronteiras.

Se num primeiro momento as relações do homem com a natureza eram permeadas pelos mitos e com a presença de uma relação quase divina, com o passar do tempo, se teve uma relação antropocêntrica do mundo, onde o homem passou a ser o centro, o senhor de todas as coisas, em oposição à natureza. Essa modificação de orientação fez com que se passe a ver a natureza tão somente como um recurso, que existe para atendimento das necessidades humanas.

O uso indiscriminado dos recursos naturais levou à exaustão de muitos deles e colocou em perigo outros tantos, consequência disto é que, iniciada a década de 60 , surge um movimento que busca mobilizar a sociedade para que atente aos problemas ambientais. Porém, a "sustentabilidade e o desenvolvimento sustentável são frases em moda hoje em dia, muito usados mais para exposição na mídia do que preocupações reais e, infelizmente, mais através de retórica do que ação" (CRISTINA, 2014; p.498). 
De acordo com Gabriele et al (2012), Cristina (2014), pode-se observar que ao longo dos anos a sociedade vem buscando alertar para a problemática ambiental. Diferentes eventos foram realizados merecendo destaque: a Conferência Mundial sobre Meio Ambiente realizada na Suécia, no ano de 1972, quando foi assinado o Tratado de Estocolmo; a criação do Programa das Nações Unidas para o Meio Ambiente (PNUMA); o Protocolo de Montreal, que busca discutir soluções para mitigar a deterioração da camada de ozônio, no final da década de 80; no Brasil, em 1992, realizou-se a Conferência Mundial para o Desenvolvimento e o Meio Ambiente, a Rio 92; em 1997, a Conferência das Partes III, que foi uma ação considerada fundamental; no ano de 2002, em Johanesburgo, África do Sul, foi realizada a Rio+10; entre outras.

Para Wells (2013), a aplicação do pensamento ambiental, e o tema mais amplo de sustentabilidade, no mundo dos negócios se desdobrou ao longo de muitos anos. Segundo o autor, a relação entre negócios e sustentabilidade tornou-se um dos debates centrais para o futuro, tanto nos países que já experimentaram a industrialização, quanto naqueles que estão a sofrer o impacto transformador deste processo.

Diferentes autores apresentam conceitos para a gestão ambiental, entre eles Donaire (2012), que afirma que a gestão ambiental é um processo adaptativo e contínuo, onde as empresas definem e redefinem seus objetivos e metas relacionados à proteção do ambiente, à saúde de seus empregados, bem como dos clientes e da comunidade.

Tomando por base os diferentes interesses de cada uma das partes, as empresas precisam definir estratégias que permitam a intervenção, sem prejuízo ao ambiente, mantendo atenção às questões de avaliação constante de suas ações, bem como uma intensa interação com o meio externo à empresa, de forma a garantir um constante aporte de informações, que lhe permita avançar. A sustentabilidade só pode ser alcançada quando há "concomitantemente desempenho econômico, social e ecológico" (VELLANI e RIBEIRO, 2009; p.27).

A gestão ambiental é a parte da função gerencial que trata, determina e implanta a política de meio ambiente estabelecida pela empresa, sendo esta política, a declaração de comprometimento da empresa com o meio ambiente. 
De acordo com Gabriele et al (2012), a gestão ambiental deve ter presente a necessidade de uma visão sistêmica, deixando de ser "uma função exclusiva da produção" (DONAIRE, 1994; p.70) e ser incorporada em todos os níveis organizacionais, como diria Jabbour et. al (2012), fazendo com que as diferentes áreas possam atuar de forma proativa, trazendo a possibilidade de resultados positivos advindos das práticas de gestão ambiental.

As decisões empresariais, de acordo com Teixeira e Bessa (2009) deveriam pautar-se não somente por uma racionalidade econômica, mas também considerar as questões ambientais, ultrapassando a irracionalidade da modernidade industrial que coloca sobre os empresários a pressão do mercado, o que pode levar a riscos ambientais e sociais.

De acordo com Ceruti e Silva (2009), um Sistema de Gestão Ambiental (SGA) pode ser definido como um conjunto de procedimentos para gerir ou administrar uma organização, de forma a obter o melhor relacionamento com o meio ambiente. Um sistema de gerenciamento ambiental, em síntese, representa a estratégia empresarial para a identificação de possíveis melhorias dos processos a serem realizadas, com o intuito de conciliar definitivamente a lucratividade empresarial com a proteção do ambiente. Segundo Ramalho e Sellitto (2013) é parte integrante da estratégia, a finalidade de responder à demanda social por um desenvolvimento ambientalmente correto.

O propósito dos sistemas de gestão ambiental pode ser sintetizado, de acordo com Oliveira e Pinheiro (2010), como sendo uma possibilidade de organizar, coordenar e monitorar as atividades organizacionais relacionadas ao meio ambiente.

Como diriam Costa, Silva e Mattos (2012), as decisões deveriam ser tomadas a partir de uma abordagem transdisciplinar, admitindo que em virtude da complexidade que envolve as questões ambientais, seria necessário um conjunto de conhecimentos em diferentes áreas, desde modelos especializados até conhecimentos gerais.

Importante ter presente que a estrutura organizacional deveria contemplar a gestão ambiental, porém, como afirma Corazza (2003) não basta criar um departamento, a incorporação da dimensão ambiental deve se dar em todas as áreas da empresa, caso contrário ter-se-á pouca efetividade nas ações desenvolvidas, sendo que "a estruturação dependerá do tamanho, setor de atuação, 
complexidade e disponibilidade de recursos organizacionais" (SEIFFERT, 2007; p.39).

A gestão ambiental pode ser encarada como uma função ampla perpassando os diferentes elos de uma cadeia produtiva. A partir disto, é preciso que se considere a gestão ambiental, pois como diria Karagülle (2012) o desenvolvimento sustentável é um dos pilares da gestão estratégica, passando de uma simples análise do setor produtivo a uma análise de toda a cadeia produtiva, envolvendo desde os fornecedores de matéria-prima até os consumidores finais.

Esta prática tem permitido que algumas empresas sejam capazes de "ganhar dinheiro e proteger o meio ambiente ao mesmo tempo" (DONAIRE, 2012; p.51), viabilizando o que Porter (1999) chamava de verde e competitivo. "Embora o principal objetivo de uma empresa seja o lucro" (OLIVERIA e SERRA, 2010; p.429), pode-se afirmar que o "crescimento econômico e a proteção ambiental devem estar obrigatoriamente associados" (TEIXEIRA e BESSA, 2009; p.7).

Não obstante, o envolvimento das empresas em relação ao Sistema de Gestão Ambiental não ter se dado com a mesma velocidade e intensidade, há setores em o processo ocorreu rapidamente (principalmente nos tidos como mais poluidores, como: o petroquímico, a celulose, o metalúrgico), tendo em vista a preocupação em demonstrar para a sociedade o comprometimento com a ideia de sustentabilidade. A busca de tornar a produção mais racional, diminuindo os desperdícios e com melhor gerenciamento do uso dos insumos, tem consolidado a mudança de comportamento empresarial.

A iniciativa de modificar os processos, reduzindo operações dispendiosas, tem possibilitado uma economia de recursos e viabilizado um incremento na produtividade, o que vem trazendo maior eficiência com menor agressão ao meio ambiente.

De acordo com Teixeira e Bessa (2009), principalmente o setor industrial tem mostrado avanços no que diz respeito aos problemas ambientais, a partir do momento em que passaram a vê-los como uma oportunidade para o aumento da competitividade. É preciso ter presente que esta atitude se encontra em diferentes estágios, pois como afirma Seiffert (2007) deve-se observar as especificidades do tipo de indústria, uma vez que há diferentes impactos, a partir do ramo de atividade. 
É preciso entender que os processos produtivos passaram por uma evolução de acordo com as suas práticas ambientais que, segundo Vanalle, Lucato e Santos (2011), foram: a) sistemas de produção tradicionais - com base na eliminação de resíduos como um princípio; b) sistemas de produção Lean - redução de resíduos para uma melhor utilização dos recursos; c) sistemas de produção Verde - aplicar o princípio da R3 (reduzir, reutilizar ou reciclar os resíduos); d) sistemas de produção sustentáveis - aplicar o princípio da 6 do R (reduzir, reutilizar, reciclar, recuperar, reestruturar e refabricar).

Foi necessário avançar para além das soluções de fim de tubo. Para tanto, as empresas passaram a desenvolver Sistemas de Gestão Ambiental que "podem ser descritos como uma metodologia pela qual as organizações atuam de maneira estruturada sobre suas operações para assegurar a proteção ao meio ambiente" (OLIVERIA e SERRA, 2010; p.430), sendo possível afirmar que possuem como objetivo, melhorar o desempenho ambiental e econômico, diminuindo a demanda por recursos naturais e aumentando a produtividade.

Para que se possa ter um Sistema de Gestão Ambiental institucionalizado na organização é preciso destacar alguns aspectos nos quais deverá se basear, sendo que as etapas para a implantação de um SGA são apresentadas de diferentes formas, mas é possível afirmar que passam por:

a) definição de uma política ambiental que pode ser conceituada como a posição adotada por uma organização relativamente ao ambiente;

b) planejamento que deve iniciar pela identificação dos pontos fortes e fracos da organização e avaliação do impacto de cada um no meio ambiente;

c) a empresa deve estabelecer e manter procedimentos para identificar os aspectos ambientais que controla e sobre os quais exerce alguma influência, devendo igualmente garantir que os impactos por eles provocados estão considerados no estabelecimento da sua política ambiental.

Em um programa de gestão ambiental, os objetivos ambientais a estabelecer e manter devem ser considerados relevantes para a organização. Elaborado o planejamento deve-se passar para a etapa da implementação, quando regras, responsabilidades e autoridades são definidas, documentadas e informadas às partes interessadas. Para tanto devem ser providas as condições tecnológicas, bem como de recursos humanos qualificados. 
A partir do momento em que se concretizam as ações é necessário que se estabeleça uma sistemática de avaliação e de possíveis ações corretivas, com a finalidade de aperfeiçoar o sistema continuamente e como decorrência da avaliação a direção poderá estabelecer alterações e a uma maior eficácia do sistema.

Uma das alternativas para o estabelecimento de um Sistema de Gestão Ambiental é a adoção das normas da série ISO 14001, que estabelece uma série de requisitos que possibilitam o desenvolvimento de objetivos e políticas ambientais que atendam à legislação, pois como afirmam Brito, Cunha e Cunha (2012) a legislação torna-se cada vez mais restritiva e exigente no controle, monitoramento e fiscalização de impactos ambientais causados pelos empreendimentos de modo geral.

Porém, mais do que isto, permite estabelecer uma dinâmica de melhoria contínua nos processos e produtos, levando a incremento nos resultados financeiros, melhoria no trato com os colaboradores e na imagem pública da empresa, aumento da satisfação dos clientes, entre outros. Corazza (2003) afirma que, conforme a implantação da ISO 14001 progride, avança a integração matricial da gestão ambiental. Corroborando Oliveira e Serra (2010) afirmam que a gestão ambiental é uma alternativa real, cada vez mais utilizada pelas empresas para melhorar seus processos e consequentemente prejudicar menos o meio ambiente e a norma ISO 14.001 tem sido o instrumento mais utilizado para isto.

Wells (2013) destaca que há um rico campo teórico e metodológico para quantificar o impacto ambiental dos diferentes processos de produção e que é possível comparar diferentes maneiras de fazer o mesmo produto, com menor impacto ambiental nas cadeias produtivas. Entre as ferramentas importantes para a gestão ambiental estão: contabilidade ambiental, análise do fluxo de materiais, análise do fluxo de energia, indicadores de infraestrutura e de transporte, análise do ciclo de vida, que segundo Hansen, Seo e Kulay (2010) pode ser entendida como uma técnica de avaliação quantitativa, voltada a determinação de impactos ambientais associados ao exercício da função de um produto, relatório ambiental.

Vasile e Man (2012) dizem que a contabilidade ambiental é definida como o processo de identificação, coleta, cálculo (estimativa), análise, relatórios internos e uso de informações sobre materiais e energia, os custos ambientais bem como de outros dados relativos a custos dentro de processo decisório, a fim de adotar as 
decisões convenientes capazes de contribuir para a proteção do ambiente. Partindo deste conceito é possível afirmar que a contabilidade ambiental tem como objetivo principal a emissão de dados úteis para a tomada de decisão, proporcionando o desenvolvimento sustentável da atividade.

Importante destacar Rosa et al (2010), quando afirmam que a avaliação ambiental requer uma reformulação na contabilidade tradicional levando-a a ser capaz de identificar, mesurar, avaliar e evidenciar os elementos ambientais, superando a visão tradicional dos aspectos financeiros e econômicos tão simplesmente, pois como dizem Vasile e Man (2012), infelizmente, os métodos de contabilidade tradicionais não oferecem a estrutura ideal capaz de identificar as questões ambientais, pois os dados geralmente se concentram sobre os custos. Para mudar esta situação foi fundamental, segundo o ponto de vista de AureliaAurora e Sorina-Geanina (2012), o envolvimento de profissionais contabilistas na pesquisa e no desenvolvimento de desta área.

\section{PROCEDIMENTOS METODOLÓGICOS}

Este trabalho foi desenvolvido a partir de dados publicados pela Análise Editorial, que nos últimos sete anos vem pesquisando as principais práticas de gestão ambiental nas empresas brasileiras. Tomou-se por base a sétima edição do anuário Análise Gestão Ambiental que contemplou 853 empresas, 25 bancos e 237 Organizações Não Governamentais, sendo avaliados 28 diferentes ramos da economia.

Em relação à natureza, a pesquisa está classificada em aplicada ou tecnológica, uma vez que gera conhecimentos resultantes do processo, além de possibilitar sua aplicação. Quanto ao método de abordagem do problema, o estudo é quantitativo, pois busca estabelecer um comparativo entre os resultados das empresas nascidas no RS e os resultados das demais empresas brasileiras (incluísse das nascidas no RS), no que diz respeito às suas práticas de gestão ambiental. Quanto aos fins, o estudo é descritivo, porque expõe as características das diferentes empresas. Quanto aos meios, o estudo se valeu de pesquisa bibliográfica e de dados secundários. 
Realizou-se contato com a Editora para verificar a possibilidade de acessar os dados da pesquisa, sendo prontamente viabilizado. Os dados solicitados à Revista Análise Gestão Ambiental contemplam informações das empresas nascidas no RS e brasileiras. Foram solicitados dados quanto: a) a existência de uma política ambiental; b) a que posição hierárquica as questões ambientais estão subordinadas; c) como procedem as empresas no que diz respeito ao reuso da água; d) como controlam as emissões atmosféricas; e) a produção de resíduos; f) se fazem uso da energia solar; g) como se dão as relações com os fornecedores; h) práticas; i) certificação ISO 14001; j) treinamento; k) estrutura; I) relacionamento com fornecedores; m) políticas de divulgação; e n) sistemas de informação.

Visto o grande número de questões, optou-se por desconsiderar as que faziam referência aos aspectos tecnológicos, focando sobre as questões de gestão ambiental.

De posse dos dados realizou-se a identificação das empresas "nascidas" no Rio Grande do Sul. Uma vez localizadas, e de posse do banco de dados da Editora Análise, realizou-se a extração dos dados referentes às mesmas, sendo estes tabulados, permitindo assim a comparação.

Optou-se por não incluir as Organizações não Governamentais e os bancos, centrando a atenção nas empresas. Foram localizadas 49 empresas nascidas no RS, entre indústrias e prestadoras de serviços, o que representou 5,75\% das empresas originalmente pesquisadas pela Editora Análise.

As empresas podem ser subdivididas em dois subgrupos: indústria- comércio (33 organizações) e prestação de serviços (16 organizações). As indústrias contemplam 31 empresas, sendo que a maior frequência se dá no segmento de alimentos e metalurgia (10 organizações em cada um dos segmentos), seguido de química e madeira (3 organizações cada), papel e celulose, têxtil, calçados, borrachas e energia.

Como o número de empresas por segmento é pequeno, não é recomendável realizar uma análise mais pormenorizada dos dados, pois ter-se-ia dificuldade de realizar inferências estatísticas válidas. Assim, optou-se por realizar uma comparação entre as empresas do setor alimentício e metalúrgico, nascidas no RS, e a comparação geral entre as nascidas no RS e as demais empresas do Brasil. 


\section{APRESENTAÇÃO E DISCUSSÃO DOS RESULTADOS}

Como dito apresentado anteriormente, o número de empresas por segmento é pequeno, sendo temeroso realizar análises mais específicas. Desta forma, teve-se de trabalhar com dados agregados, porém mesmo com a impossibilidade de extrapolar os resultados fez-se uma avaliação das indústrias que apresentaram maior frequência entre as nascidas no RS.

Observando as empresas dos setores de metalurgia e alimentação (que foram as que apresentaram maior frequência) foi possível encontrar diferenças importantes que apontam para um desenvolvimento maior das primeiras, quando se fala de gestão ambiental.

Em relação a existência de uma política ambiental integrada com as demais políticas da empresa, as empresas alimentícias só estão presentes em 30\%, enquanto que no segmento da metalurgia, o percentual sobe para $80 \%$, demonstrando assim, uma preocupação maior do setor. Corroborando esta afirmação pode-se constatar que $70 \%$ das empresas metalúrgicas possuem certificação ISO 14001, contra somente 10\% das alimentícias. Cabe destacar ainda, que as primeiras se valem de outras ferramentas tais como: auditorias ambientais, avaliação de performance a partir de indicadores e ferramentas de comunicação, o que não se constata nas segundas.

A responsabilidade pela gestão ambiental está declarada no organograma de $80 \%$ das empresas metalúrgicas, contra $40 \%$ das alimentícias, estando vinculadas as áreas de meio ambiente e segurança e saúde do trabalhador especificamente, e subordinadas à Diretoria (70\% nas metalúrgicas) ou à Gerência $(30 \%$ nas alimentícias).

$\mathrm{Na}$ relação com os fornecedores, ambos segmentos realizam exigências ambientais, porém, as alimentícias são menos rigorosas, somente $20 \%$ delas condicionam à aquisição ao atendimento de questões legais (70\%), enquanto que 80\% das empresas metalúrgicas realizam a exigência e para além do legal exigem que sejam apresentadas certificações e outras normas específicas.

Finalizando, dois outros aspectos foram alvo de comparação: a realização de atividades de treinamento e ações de comunicação. Mais uma vez observa-se que as empresas do segmento metalurgia estão mais voltados para as questões 
ambientais, pois realizam treinamentos com funcionários e terceiros (80\%) e com fornecedores (50\%). Enquanto que as empresas alimentícias se dedicam somente aos funcionários (60\%) ou não realizam ações de treinamento (40\%). Já nas questões de comunicação, $60 \%$ das empresas metalúrgicas publicam seus resultados ambientais de forma sistematizada, contra somente $30 \%$ das empresas alimentícias.

Os resultados em todos os itens são favoráveis às indústrias metalúrgicas, a hipótese é que este setor por sua característica mais poluidora seja mais regulamentado e por isto invista mais em gestão ambiental, algo a ser investigado posteriormente.

Apresentam-se agora os resultados encontrados a partir da tabulação dos dados, comparando as empresas nascidas no RS com as demais empresas brasileiras.

No que diz respeito à existência de uma política ambiental declarada pode-se observar que as empresas nascidas no RS se encontram em igualdade de condições com as demais empresas brasileiras, embora os resultados pudessem ser melhores, pois ainda há cerca de um terço das empresas que não possuem uma política ambiental definida. Torna-se importante destacar que a existência de uma política ambiental por si só, não representa a garantia de uma boa gestão, mas é ponto de partida para tal.

Uma ferramenta que tem sido utilizada para direcionar a gestão ambiental nas empresas é a Certificação ISO 14001. Como pode ser visto na tabela 1, as empresas nascidas no RS estão em desvantagem, com menos de um terço delas certificadas, enquanto isto no Brasil, o resultado é cerca de um meio. Interessante destacar que a segunda maior freqüência, de $29,17 \%$, indica que as empresas não visualizam a necessidade de implantá-la.

Contudo, quando somadas às alternativas: não possui, mas planeja implementar e não, mas está cumprindo os requisitos para obter a certificação, temse $41,66 \%$, o que indica existir sim uma preocupação com a busca do certificado. 
Tabela 1 - Empresas certificadas

\begin{tabular}{lcc} 
Possui certificação ISO 14001 & Brasil \% & RS \% \\
\hline Possui & 50,80 & 29,17 \\
Não possui, mas planeja implementar & 21,00 & 20,83 \\
$\begin{array}{l}\text { Não possui, mas está cumprindo as etapas para obter a } \\
\text { certificação }\end{array}$ & 14,20 & 20,83 \\
$\begin{array}{l}\text { Não possui e não vê necessidade da certificação no } \\
\text { momento, para a sua atividade }\end{array}$ & 14,00 & 29,17 \\
Total & 100,00 & $\mathbf{1 0 0 , 0 0}$ \\
\hline
\end{tabular}

Fonte: dados coletados

Além de ter um menor percentual de empresas certificadas, o Rio Grande do Sul também começou o processo mais tardiamente, denotando um atraso em relação às demais empresas do país. No Brasil prevalecem às certificações com mais do que cinco anos, demonstrando certa maturidade do processo de gestão ambiental. Nas empresas nascidas no RS, o percentual é menor, embora prevalente, tendo $36 \%$ de empresas certificadas há menos de cinco anos.

Complementarmente à norma ISO 14001 outras ferramentas estão sendo utilizadas pelas empresas, como pode ser visto no gráfico 1. Há uma prevalência das auditorias ambientais seguida da avaliação de performance. Observe-se que as empresas nascidas no RS utilizam as mesmas ferramentas que as demais empresas brasileiras. No entanto com uma intensidade menor. O uso das auditorias é de 84\% nas empresas brasileiras e de somente 39,50\% nas empresas nascidas no RS. A exceção é a ferramenta de análise do ciclo de vida dos processos da qual 23\% das empresas nascidas no RS fazem uso contra somente $8,6 \%$ das empresas brasileiras. 
Gráfico 1 - Ferramentas utilizadas

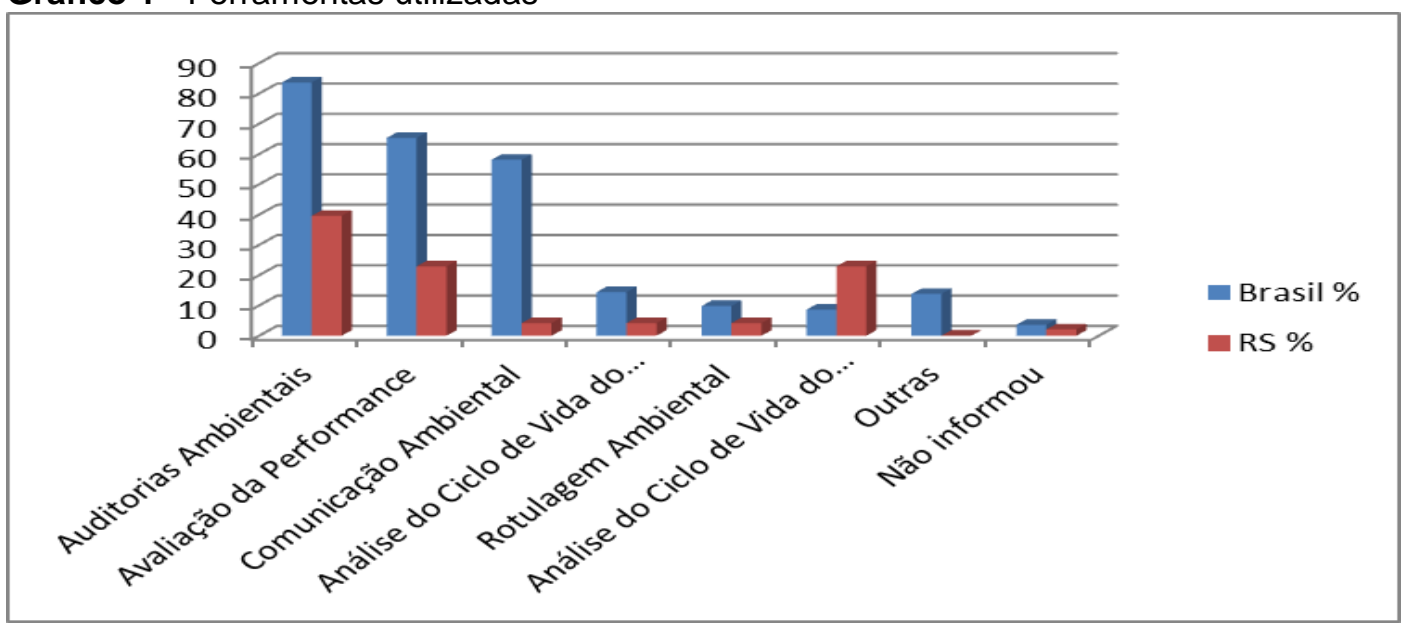

Fonte: dados coletados

No que diz respeito à existência de programas de melhorias, as empresas brasileiras estão à frente das nascidas no RS. Chama a atenção o percentual de empresas nascidas no RS que se valem da informalidade para a apresentação destes programas. A busca da melhoria contínua é um dos preceitos básicos das normas da série ISO, uma vez que os processos devem ser monitorados de forma a avaliar as oscilações, possibilitando a constatação de possíveis desvios que extrapolem a normalidade. Ademais, mesmo que o processo esteja controlado, melhorias podem ser buscadas.

Um procedimento importante para que se possam implantar melhorias, diz respeito à qualificação dos atores envolvidos: funcionários, fornecedores, terceiros e, por que não dizer, a comunidade como um todo. Investir em pessoas é fundamental para criar uma consciência ambiental, pois a responsabilidade pela preservação dos recursos naturais não é exclusiva das empresas, senão da sociedade.

Mais uma vez os percentuais das empresas nascidas no RS são menores do que os das demais empresas brasileiras. A menor diferença está no item que diz respeito ao treinamento dos fornecedores ( 8,6 pontos percentuais), e as maiores diferenças nas variáveis de funcionários e comunidade (14 pontos percentuais de diferença). Considerando que os investimentos em treinamento podem ser dispendiosos, é possível entender porque as empresas concentram os mesmos nos funcionários, $99,6 \%$ e 85,42\% nas empresas brasileiras e nascidas no RS, respectivamente, em comparação a 35,2\% e $20,83 \%$ na comunidade. Há 
necessidade de buscar mensurar a eficácia destes treinamentos, constituindo uma oportunidade de futuras pesquisas.

Quanto à forma de apresentação da responsabilidade ambiental, 84,3\% das empresas brasileiras o fazem declaradamente em seus organogramas, enquanto que nas empresas nascidas no RS este percentual cai para 66,67\% e em 31,25\% delas a declaração é informal. O não estabelecimento de uma instância formal para ser a responsável pela gestão ambiental nas empresas pode levar a uma condição na qual todos são responsáveis e paradoxalmente ninguém o é de fato. Pode-se afirmar que é fundamental deixar claro a que área, departamento ou pessoa as questões ambientais estão diretamente ligadas.

É possível confirmar o apresentado durante a revisão teórica há uma diversidade de opções no que diz respeito a que área a gestão ambiental está vinculada (gráfico 2). Pode-se observar que prevalece a vinculação ao Sistema de Gestão com 28,1\% nas empresas brasileiras e 0\% nas empresas nascidas no RS.

Quando a vinculação se dá no nível de segurança e saúde, as empresas nascidas no RS têm uma leve vantagem em relação às demais empresas brasileiras com 10,42\%, contra 4,7\%, respectivamente. Mas o que mais chama a atenção e confirma a diversidade de modelos adotados pelas empresas é o percentual da alternativa "Outra" onde, no Brasil, 16,8\% das empresas vincula a "outra" não constante da relação apresentada aos respondentes. Nas empresas nascidas no RS este percentual sobe para $35,41 \%$.

Gráfico 2 - Área a qual está vinculada a gestão ambiental

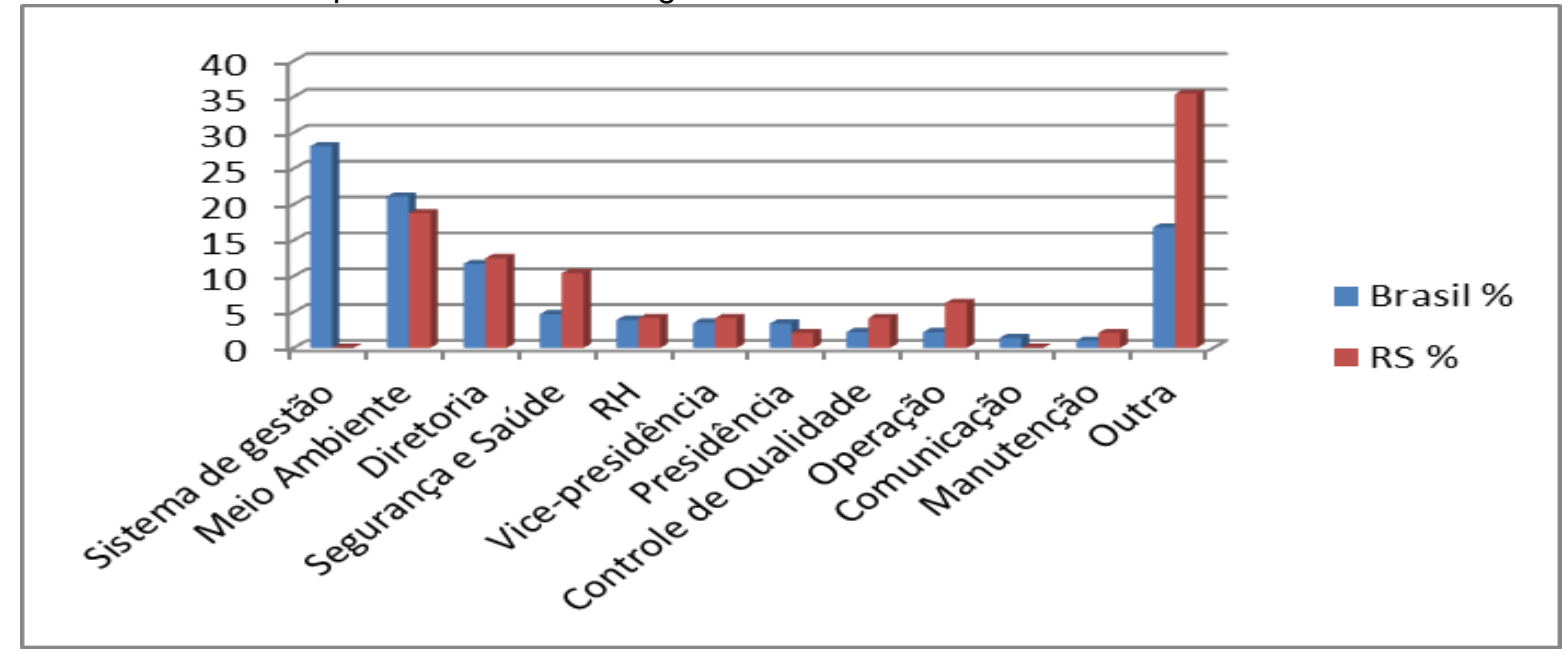

Fonte: dados coletados 
A prevalência é do nível diretoria com uma leve vantagem para as empresas nascidas no RS com 52,08\%, para 49\% das demais empresas brasileiras se reportando a este nível, porém quando a vinculação é diretamente à presidência, os percentuais são 10,42\% para as empresas nascidas no RS e 18,7\% para as demais empresas brasileiras (ver tabela 2). Tomando por verdadeira a premissa de que a principal liderança da empresa é que deve capitanear o processo, é possível afirmar que as empresas nascidas no RS e brasileiras estão no caminho certo por vincularem a gestão ambiental à cúpula das organizações.

Tabela 2 - Nível hierárquico ao qual está vinculado o Sistema de Gestão ambiental

\begin{tabular}{lcc} 
A que nível organizacional se reporta a área ambiental & Brasil \% & RS \\
\hline Diretoria & 49,00 & 52,08 \\
Presidência & 18,70 & 10,42 \\
Gerência & 15,70 & 20,83 \\
Vice-presidência & 9,80 & 2,08 \\
Superintendência & 3,50 & 4,17 \\
Chefia & 1,20 & 4,17 \\
Técnica & 0,60 & 4,17 \\
Supervisão & 0,40 & 2,08 \\
Liderança & 0,10 & 0,00 \\
Outra & 1,00 & 0,00 \\
\hline Fon
\end{tabular}

Fonte: dados coletados

Mais importante do que vincular a cúpula da organização é tê-la atuante no processo de gestão ambiental. Neste sentido, o conhecimento dos impactos ambientais da atividade é reportado à administração de uma forma documentada em $81,7 \%$ das empresas brasileiras, contra 70,83\% das empresas nascidas no RS. Destaca-se ainda, que a atuação sobre os impactos só pode ser realizada à medida que a administração toma conhecimento dos mesmos.

Com os percentuais apresentados é possível afirmar que a situação das empresas nascidas no RS poderia ser melhor, caso o percentual de comunicações informais fosse menor do que os atuais $29,17 \%$, pois os registros tornam-se 
fundamentais para que se possa manter o histórico das atividades e com base neles tomar decisões que evitem possíveis erros ocorridos em determinado momento.

Os processos nos quais o conhecimento chega à cúpula são mais amplos do que somente os vinculados ao processo produtivo, como prevalecia no passado. Atualmente dá-se a conhecer os problemas que se referem às atividades, aos terceirizados, aos fornecedores, bem como aos processos administrativos.

Neste aspecto, as empresas nascidas no RS estão atrasadas, pois em $39,60 \%$ das empresas só se leva ao conhecimento da cúpula, os impactos dos processos produtivos e administrativos, contra 28,30\% nas demais empresas brasileiras. Tem-se aqui uma oportunidade de melhoria, uma vez que, quanto mais a cúpula souber sobre os diferentes impactos, melhores e mais rápidas poderão ser as decisões.

Na relação com os fornecedores as empresas nascidas no RS têm sido mais críticas com 56,25\% exigindo que os fornecedores comprovem procedimentos de gestão ambiental, contra 52,60 das demais empresas brasileiras. Porém, as exigências prevalentemente estão no atendimento à legislação. Embora mais exigentes, as empresas nascidas no RS são menos rigorosas quando o assunto é o certificado ou outras exigências formais.

No que diz respeito as ações de comunicação, mais uma vez se percebe uma diversidade de ações e para distintos públicos. Nas empresas nascidas no RS prevalecem as ações direcionadas ao público em geral (56,25\% das ações), já nas demais empresas brasileiras prevalecem às ações direcionadas às escolas. Neste item é temerário afirmar que uma opção ou outra seja a melhor, mas tem-se como senso comum que buscar atingir as crianças, o que seria possível via ações junto às escolas, pode trazer melhores resultados futuros. De modo geral, as empresas nascidas no RS, independentemente do tipo de ação, demonstram uma menor preocupação com os processos de comunicação, no que diz respeito a sua gestão ambiental.

Para além das ações de comunicação, as empresas têm desenvolvido projetos (gráfico 3), sendo 56,25\% das empresas nascidas no RS e $77 \%$ das demais empresas brasileiras respectivamente, de cunho educacional, sendo $35,42 \%$ nas empresas nascidas no RS e 75,80\% nas demais empresas brasileiras, também são desenvolvidas ações voltadas para os professores. Independentemente das ações 
desenvolvidas as empresas nascidas no RS estão em desvantagem em relação às demais empresas brasileiras.

Gráfico 3 - Projetos ambientais desenvolvidos pelas empresas

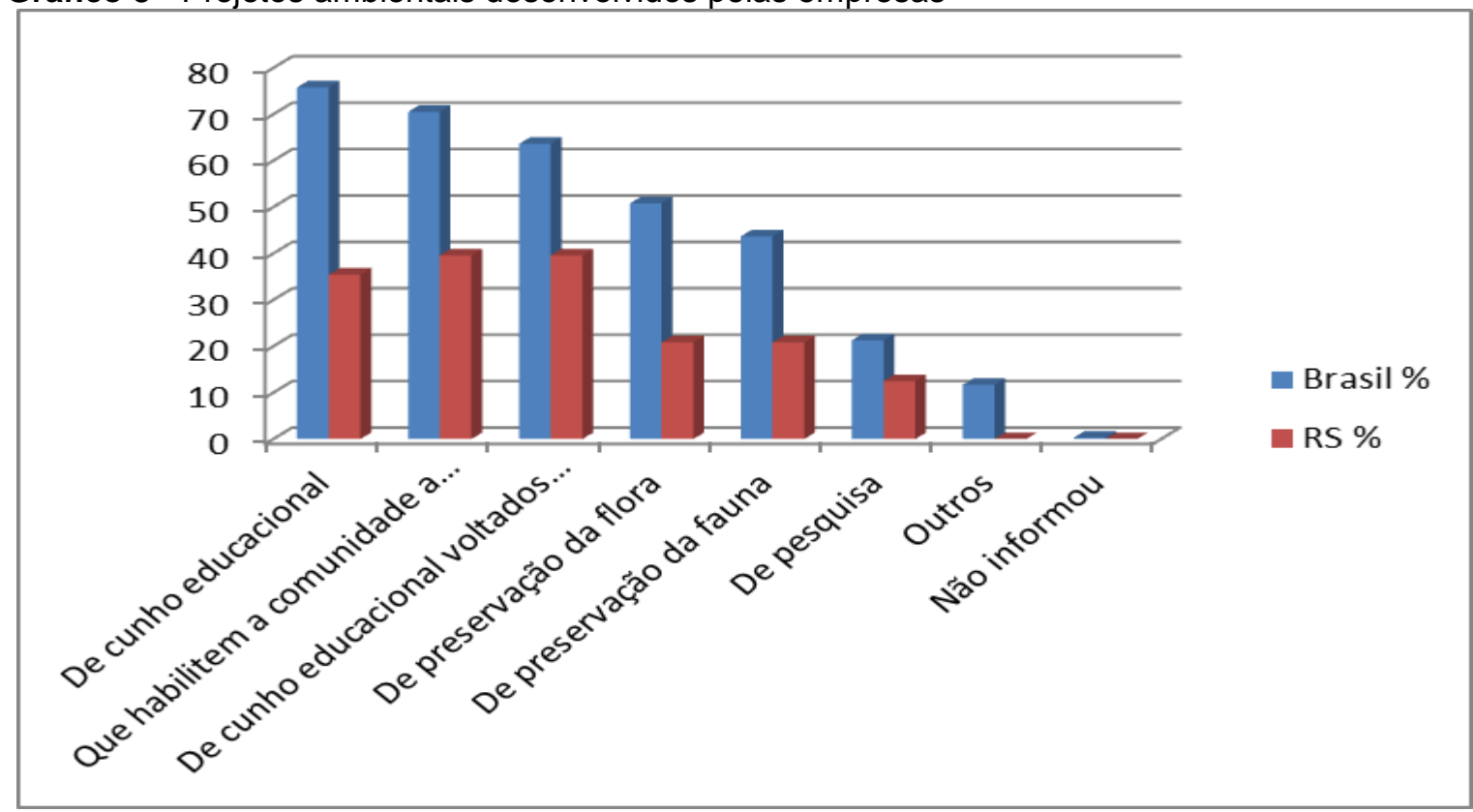

Fonte: dados coletados

Os meios utilizados para publicar as informações relativas às práticas de gestão ambiental das empresas têm sido o uso do sítio da empresa na internet, seguido de relatório anual. Em ambos os itens, as empresas nascidas no RS apresentam percentuais inferiores às demais empresas brasileiras. As empresas nascidas no RS apresentam um percentual maior somente na categoria "outros" com 45,83\%. Considerando que algumas ferramentas são mais aceitas no cenário empresarial, como por exemplo os relatórios do modelo Ethos, tanto as empresas nascidas no RS como as demais ainda possuem um grande espaço para avançar.

\section{CONCLUSÕES}

Os instrumentos mais utilizados para gerir a questão ambiental nas empresas são a Norma ISO 14001, seguida de Auditorias ambientais. São ainda utilizadas exigências junto aos fornecedores, induzindo-os a adotar práticas de gestão ambiental em suas organizações, entre outras. 
$\mathrm{Na}$ comparação com as demais empresas brasileiras, o desempenho das empresas nascidas no RS pode ser considerado defasado. Os percentuais apresentados são, em quase todos os aspectos avaliados, menores, demonstrando que ainda há uma série de oportunidades a serem aproveitadas na direção da melhoria da gestão ambiental.

$\mathrm{Na}$ continuidade pode-se realizar um estudo tendo como objeto as ONGs, bem como a realização de uma avaliação comparando o desempenho dos diferentes setores.

\section{AGRADECIMENTOS}

À Editora Análise pelo fornecimento do Banco de Dados.

\section{REFERÊNCIAS}

ALPERSTEDT, Graziela Dias; QUINTELLA, Rogério Hermida; SOUZA, Luiz Ricardo.

Estratégias de gestão ambiental e seus fatores determinantes: uma análise institucional. RAE, São Paulo, v. 50, n. 2, abr./jun. 2010, p.170-186.

AURELIA-AURORA, Diaconeasa; SORINA-GEANINA, Mãrgãrit Stãnescu. Perspectives of environmental accounting in Romania. Procedia - Social and Beahavioral Sciences. 62 (2012), p.610-614. http://dx.doi.org/10.1016/j.sbspro.2012.09.102

BRITO, Ângela do Céu Ubaiara; CUNHA, Alan Cavalcanti da; CUNHA, Helenilza Ferreira Albuquerque. Análise da avaliação de desempenho do sistema de gestão ambiental (ISO 14000) de usina hidrelétrica: relação empresa-comunidade do entorno. Revista Brasileira de Ciências Ambientais. n.29, jun. 2012.

CERUTI, Fabiane Cristina; SILVA, Marlon Luiz Neves da. Dificuldades de implantação de sistema de gestão ambiental (SGA) em empresas. Revista Acadêmica, Ciências Agrárias Ambientais. Curitiba: v.7, n.1, p.111-119, 2009.

CORAZZA, Rosana Icassatti. Gestão ambiental e mudanças da estrutura organizacional. RAE Eletrônica, v. 2, n. 2, jul./dez. 2003.

COSTA, Maria Isabel Lopes da; SILVA, Elmo Rodrigues da; MATTOS, Ubirajara Aluízio de Oliveira. 20 anos de eco-eficiência no Brasil: de estratégia de negócios a princípio de política pública. Revista Brasileira de Gestão e Desenvolvimento Regional, v. 8, n.1, p. 3-28, jan./abr. 2012, Taubaté, SP, Brasil.

CRISTINA, Momete Daniela. Saferational approach to a valid sustainable development.

Procedia Economics and Finance, 8, p.497-504, 2014.

http://dx.doi.org/10.1016/S2212-5671(14)00119-1 
DONAIRE, Denis. Considerações sobre a influência da variável ambiental na empresa. RAE, São Paulo, v. 34, n. 2, mar./abr., p. 68-77 1994.

DONAIRE, Denis. Gestão ambiental na empresa. São Paulo: Atlas, 2012.

GABRIELE, Pedrita Dantas; TREINTA, Fernanda Tavares; FARIAS FILHO, José Rodrigues; SOUZA, Maurício Corrêa de; TSCHAFFON, Pâmela Botelho; BRANTES, Sonia Regina. Sustentabilidade e vantagem competitiva estratégica: um estudo exploratório e bibliométrico. Revista Produção Online, Florianópolis, SC, v.12, n.3, p.729-755, 2012.

http://dx.doi.org/10.14488/1676-1901.v12i3.975

GALLARDO-VÁZQUEZ, Dolores; SÁNCHEZ-HERNÁNDEZ, María Isabel; MARTÍNEZ-AZÚA, María Beatriz Corchuelo. Validación de un instrumento de medida para la relación entre la orientación a la responsabilidade social corporativa y otras variables estratégicas de la empresa. Revista de Contabilidad - Spanish Accounting Review, v. 16, n. 1, p.11-23, 2013. http://dx.doi.org/10.1016/S1138-4891(13)70002-5

HANSEN, Adriana Petrella; SEO, Emilia Satoshi Miyamaru; KULAY, Luiz Alexandre. Identificação de oportunidades de melhoria de desempenho ambiental em processo de produção de materiais cerâmicos via aplicação da técnica de avaliação do ciclo de vida (ACV). Revista Produção Online, v.10, n.4, p.912-936, 2010.

http://dx.doi.org/10.14488/1676-1901.v10i4.526

IRIMIE, Sabin-Ioan; GAL, Jozsef; DUMITRESCU, Constantin Dan. Analysis of a dynamic regional system for the operationalizing of the sustainable development concept. Procedia Social and Behavioral Scienses, 124, p.33-338, 2014.

http://dx.doi.org/10.1016/j.sbspro.2014.02.493

JABBOUR, Charbel José Chiapetta; TEIXEIRA, Adriano Alves; JABBOUR, Ana Beatriz Lopes de Sousa, FREITAS; Wesley Ricardo de Souza. "Verdes e Competitivas?" A influência da Gestão Ambiental Desempenho Operacional de Empresas Brasileiras.

Ambiente e Sociedade, São Paulo, v. 15, n. 2, p. 151-172, maio/ago. 2012.

http://dx.doi.org/10.1590/S1414-753X2012000200009

KARAGÜLLE, Ali Özgür. Green business dor sustainable development and competitiveness: am overview of Turkish logistics industry. Procedia - Social and Behavioiral Sciense. 41, p. 456-460, 2012. http://dx.doi.org/10.1016/..sbspro.2012.04.055

KUSAKABE, Emiko. Advancing sustainable developmente at the local level: the case of machizukuri in Japanise cities. Progress in Planning, 80, p.1-65, 2013.

http://dx.doi.org/10.1016/j.progress.2012.06.001

OCAMPO, Sebastian Dueñas; PERDOMO-ORTIZ, Jesús; CASTAÑO, Lida Esperanza Villa. El Concepto de Consumo Socialmente Reponsable y su Medición. Estudios Gerenciales. 30, p.287-300, 2014. http://dx.doi.org/10.1016/j.estger.2014.01.022

OLIVEIRA, Otávio José; SERRA, José Roberto. Benefícios e dificuldades da gestão ambiental com base na ISO 14.001 em empresas industriais de São Paulo. Produção, v. 20, n.3, jul./set., p.429-438, 2010. http://dx.doi.org/10.1590/S0103-65132010005000013

OLIVEIRA, Otávio José; PINHEIRO, Camila Roberta Muniz Serra. Implantação de Sistemas de Gestão Ambiental ISO 14001: uma contribuição da área de gestão de pessoas. Gestão 
da Produção, São Carlos, v.17, n.1, p.51-61 2010. http://dx.doi.org/10.1590/S0104$\underline{530 \times 2010000100005}$

PORTER, Michael. Competição - on Competition: estratégias competitivas essenciais. Rio de Janeiro: Campus, 1999.

RAMALHO, Susan Catieri; SELLITTO, Miguel Afonso. Avaliação do desempenho ambiental de uma empresa de tratamento superficial de alumínio. Revista Produção Online, Florianópolis, SC, v.13, n.3, p.1034-1059, 2013.

http://dx.doi.org/10.14488/1676-1901.v13i3.1357.

ROSA, Fabrícia Silva da; FERREIRA, Araceli Cristina de Souza; ENSSILIN, Sandra Rolim; ENSSLIN, Leonardo. Evidenciação Ambiental (EA): Contribuição da Metodologia Multicritério para Identificação dos Aspectos Financeiros para a Gestão Ambiental. Revista

Contabilidade Vista \& Revista, Universidade Federal de Minas Gerais, Belo Horizonte, v. 21, n.4, p. 27-61, 2010.

SEIFFERT, Mari Elizabete Bernardini. ISO 14001 Sistemas de Gestão Ambiental: implantação objetiva e econômica. São Paulo: Atlas, 2007.

TEIXEIRA, Maria Gracinda Carvalho; BESSA, Eliane da Silva. Estratégias para Compatibilizar Desenvolvimento Econômico e Gestão Ambiental numa Atividade Produtiva Local. RAC, Curitiba, v. 13, p.1-18, junho 2009.

VANALLE, R. M.; LUCATO, W. C.; SANTOS, L. B. Environmental Requirements in the Automotive Supply Chain - An evaluation of a first tier company in the Brazilian auto industry. Procedia Environmental Sciences. 10, p. 337-343, 2011.

http://dx.doi.org/10.1016/j.proenv.2011.09.055

VASILE, Emilia; MAN, Mariana. Current dimension of environmental managment accounting. Procedia - Social and Behavioral Scienses, 62, p.566-570, 2012.

http://dx.doi.org/10.1016/j.sbspro.2012.09.094

VELLANI, Cassio Luiz; RIBEIRO, Maísa de Souza. Sistema Contábil para Gestão da Ecoeficiência Empresarial. Revista Contabilidade \& Finanças. USP, São Paulo, v.20, n.49, p.25-43, 2009. http://dx.doi.org/10.1590/S1519-70772009000100003

WELLS, Peter. Sustainable business models and the automotive insustry: a commentary. IIMB Management Review, 25, p.228-239, 2013.

http://dx.doi.org/10.1016/j.iimb.2013.07.001

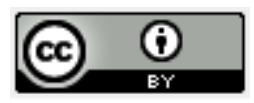

Artigo recebido em 15/07/2014 e aceito para publicação em 28/09/2015

DOI: http://dx.doi.org/ 10.14488/1676-1901.v15i4.1825 